\title{
A comparative study of operative dynamic compression plating versus non-operative management in fracture shaft of humerus
}

\author{
Naren Gaur ${ }^{1}$, Naveen Kumar Singh ${ }^{2 *}$ \\ ${ }^{1}$ Department of Orthopaedic Consultant, Shri Ram Group of Hospitals, Bikaner, Rajasthan, India \\ ${ }^{2}$ Department of Orthopaedic Surgery, North DMC Medical College and Hindu Rao Hospital, Delhi, India
}

Received: 28 November 2019

Revised: 14 January 2020

Accepted: 22 January 2020

\section{*Correspondence:}

Dr. Naveen Kumar Singh,

E-mail: 0606.naveen@gmail.com

Copyright: (C) the author(s), publisher and licensee Medip Academy. This is an open-access article distributed under the terms of the Creative Commons Attribution Non-Commercial License, which permits unrestricted non-commercial use, distribution, and reproduction in any medium, provided the original work is properly cited.

\begin{abstract}
Background: Fracture shaft of humerus is among injuries which is commonly seen in clinical practice and frequently seen in polytrauma. Humerus shaft fractures account for $3 \%$ of all orthopedic injuries. Nonoperative treatment had been the mainstay of treatment for fracture shaft of humerus earlier. The association of conservative treatment with some morbidity, complications and prolonged immobilization leads to increase in various operative modalities of management. One of the commonly used operative modality is dynamic compression plating (DCP). In view of above considerations, a study was undertaken at our hospital which aimed to compare non-operative treatment with operative DCP for the management of fracture shaft of humerus. Aims and objectives of this study to compare the results of non-operative versus operative treatment of humerus shaft fracture.

Methods: It was a prospective comparative study. Total 40 patients were taken for this study. 20 patients for operative and 20 patients for non-operative. Functional outcome was measured by the DASH scoring. P $<0.05$ was considered statistically significant.

Results: Among the 40 patients 14 had excellent results, 12 had good, 8 had fair and 6 had poor results. Functional outcome scores were better for operative group as compared to non- operative group with $\mathrm{p}<0.0001$.

Conclusions: Dynamic compression plating of humerus is better method than conservative method because it achieves higher union rates.
\end{abstract}

Keywords: Fracture shaft humerus, Dynamic compression plate, Non-operative management, Comparative study

\section{INTRODUCTION}

There is tremendous increase in trauma cases in the recent era of orthopedics. Fracture shaft of humerus is among one such injury which is commonly seen in clinical practice and frequently seen in polytrauma cases especially in road traffic accidents. Humerus shaft fractures account for $3 \%$ of all orthopedic injuries. ${ }^{1}$ It is characterized by its bimodal in age distribution, with peak in 21 to 30 years age group primarily in male patients, and the second peak being between 55 to 85 years specially in old female patients..$^{2,3}$

Conservative (nonoperative) treatment had been the mainstay of treatment for fracture shaft of humerus earlier by Sarmiento. Non-operative treatment may involve the use of functional braces, cast or some sort of splint. ${ }^{4}$ The association of conservative treatment with some morbidity and complications like non-union, malunion and persistent radial nerve deficits and the poor 
tolerance of patients towards lengthy period of immobilization and surgeon toward the more laborious effort of conservative management has however contributed to increase in operative methods of this type of fracture management, however current trend is now being changed from achieving merely the union of bone to achieve accurate length, rotational stability and perfect axial alignment. In the current scenario main focus is on to define the indications for surgical intervention, decreasing the surgical failure rate through new implants design and techniques so that we can attain the post injury rehabilitation programmed at the earliest and thereby minimizing the duration of immobilization and magnitude of remaining disability. For the same reasons and also because of the prolonged period of immobilization and associated complications with conservative management, operative modalities of treatment have emerged as the leading modality of treatment for humeral shaft fractures specially while dealing with adult population. ${ }^{5}$ The use of operative modality however complicates the treatment due to being associated with proximity to vital structures, complex injury patterns, and associated osteoporosis in elderly patients.

One of the commonly used operative modality is dynamic compression plating (DCP). Operative intervention with plates provides direct fracture visualization, allows anatomical reduction and rigid fracture fixation under vision (using dynamic compression plates). Peron et al demonstrated that compression greatly enhances the rigidity of internal fixation and in presence of such stable fixation only the internal callus achieves bone union and radiographs reveal disappearance of fracture line unlike conservative treatment where endosteal and periosteal both sides callus is formed. ${ }^{6}$ The advantages of the DCP included low incidence of malunion, stable internal fixation, and no need for external immobilization, thus allowing immediate movement of neighboring joints and an early return to normal activity. Others also conducted a multicenter study and found that plate osteosynthesis achieves far better results in fresh fractures. Plate osteosynthesis, when strict principles of AO/ASIF group are followed, most workers reported good results, the union rate varying from $95-100 \%$. $^{7,8}$

In view of above considerations, a study was undertaken at Department of Orthopedic surgery, Hindu Rao Hospital which aimed to compare non-operative treatment with operative DCP for the management of fracture shaft of humerus with following objectives in terms of time for union of fracture, functional outcome and complications.

\section{METHODS}

This was a prospective study carried out between May 2017-18 at the Department of Orthopaedics in Hindu Rao Hospital, Delhi. During this period 40 patients were studied. 20 patients of fracture shaft of humerus were treated surgically and 20 patients were treated nonsurgically.

\section{Inclusion criteria}

All patients in this study were in the age group of $18-50$ years with displaced mid shaft humerus fracture without any medical contraindication to general anaesthesia.

\section{Exclusion criteria}

Age less than 18 years or greater than 50 years, patients having pathological fracture, an open fracture and fracture with associated neurovascular deficit were kept under exclusion.

Patients were randomized to either operative or nonoperative treatment in a 1:1 ratio using random number table. Local examination was performed to note the side of limb, local tenderness, site of maximum swelling/tenderness condition of skin, bony deformity and neurovascular injury, range of motion of shoulder, elbow, wrist and fingers. associated injuries and fractures. Other associated injuries also ruled out. Appropriate Xrays of affected arm in antero-posterior and lateral view were taken and the site of fracture, amount of displacement, and the fracture type were assessed (Figure 1a). The fracture was classified according to OTA classification system. Other preoperative relevant investigations also got done.

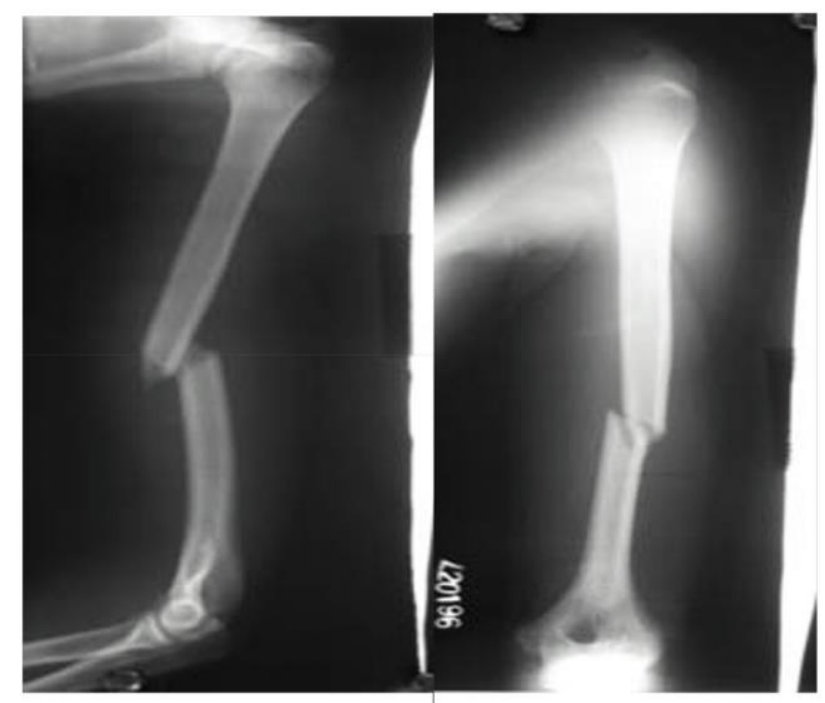

Figure 1 (a): Pre-operative X-ray of arm (AP/LAT view).

\section{Operative management}

Patients were given appropriate dose of analgesic to relieve pain and injured arm was immobilized by $\mathrm{U}$ slab. Preoperative preparation of patients as follow. A written informed consent for surgery was taken, patients were kept fasting for 6 hours before surgery and ipsilateral 
axilla, shoulder, arm and chest were prepared. A systemic antibiotic of $1 \mathrm{gm}$ of ceftriaxone was given 1 hour prior to surgery. By using anterolateral approach, a $4.5 \mathrm{~mm}$ DCP either broad or narrow according to thickness of patients humerii was used in open reduction and internal fixation of the mid shaft humerus fracture (Figure $1 \mathrm{~b}, \mathrm{c}$, $\mathrm{d}, \mathrm{e})$.

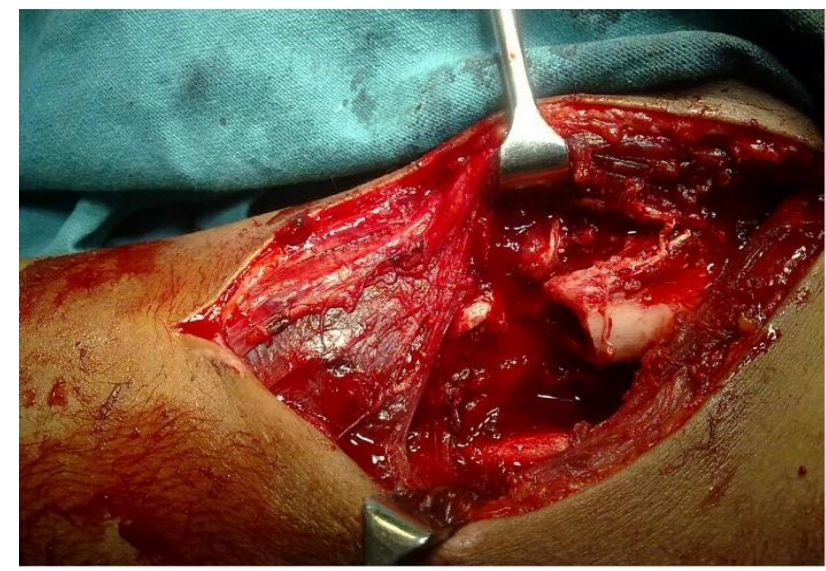

Figure 1 (b): Fracture site exposed.

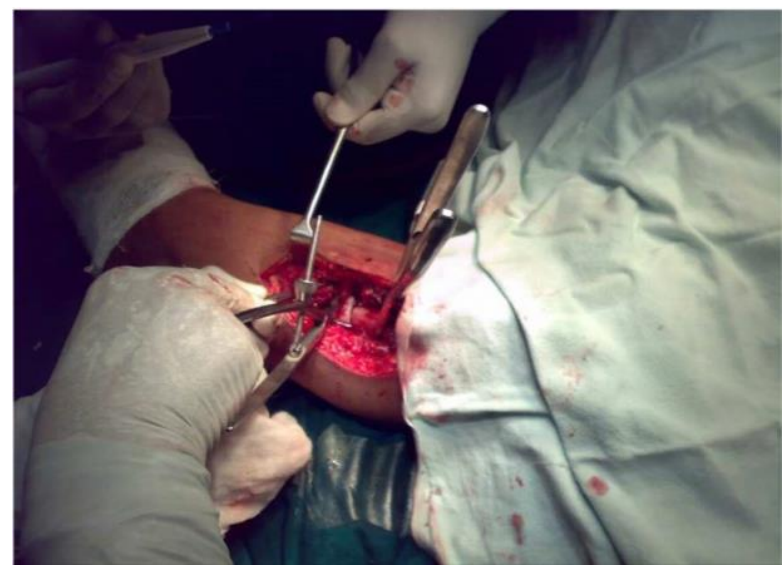

Figure 1 (c): Fracture reduced using reduction clamps.

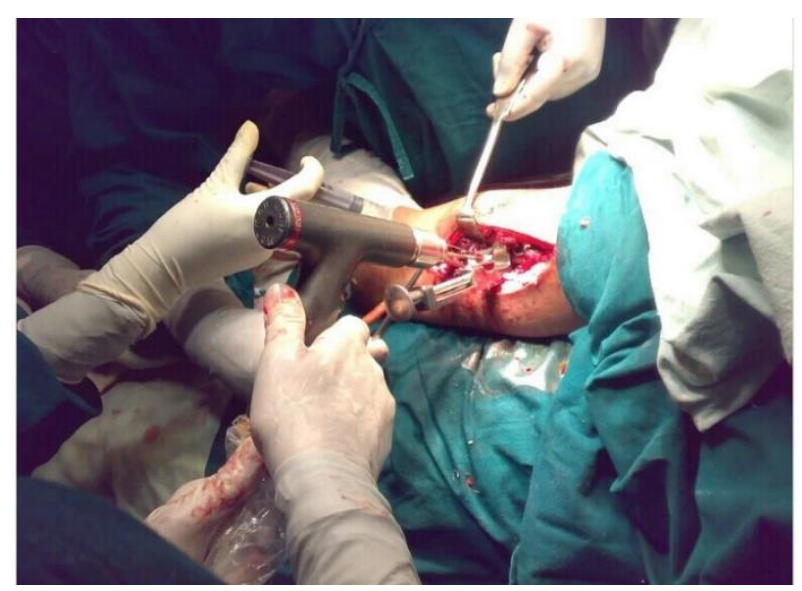

Figure 1 (d): DCP temporarily stabilized with bone holding clamps.

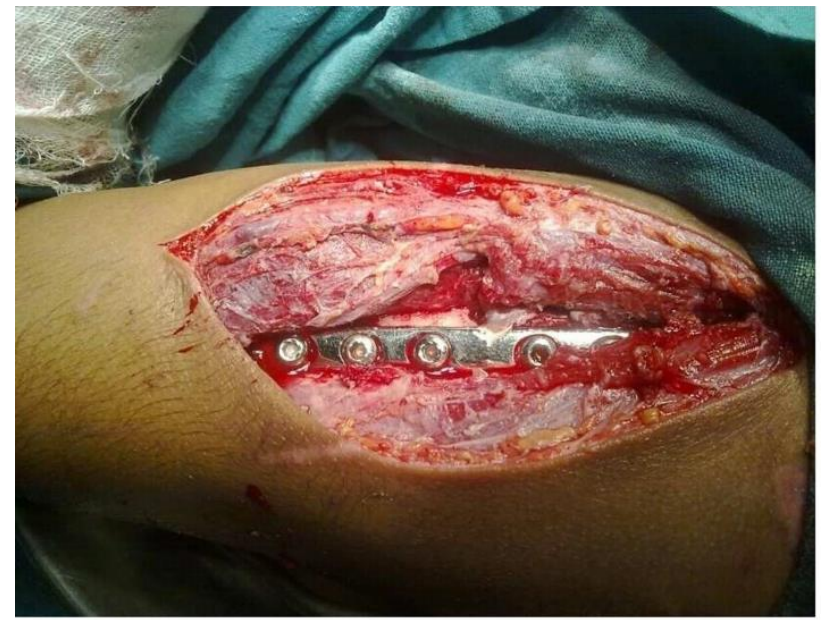

Figure 1 (e): Fracture fixed with DCP.

\section{Post-operative care}

Postoperatively antibiotics were continued for 5 days. Analgesics and tranquilizers were given according to the needs of the patient. The operated upper limb was immobilized in an arm pouch. Hand and wrist movements were started immediately post-surgery. Check X-rays were taken to study the alignment of fracture fragments (Figure 1f). The wound was inspected at $3 \mathrm{rd}$ or 4 th postoperative day. Suture removal was done on 12th postoperative day. Patients were discharged with the arm pouch. Shoulder and elbow range of motion were instituted as pain subsided. Patient was reviewed after 3 weeks.

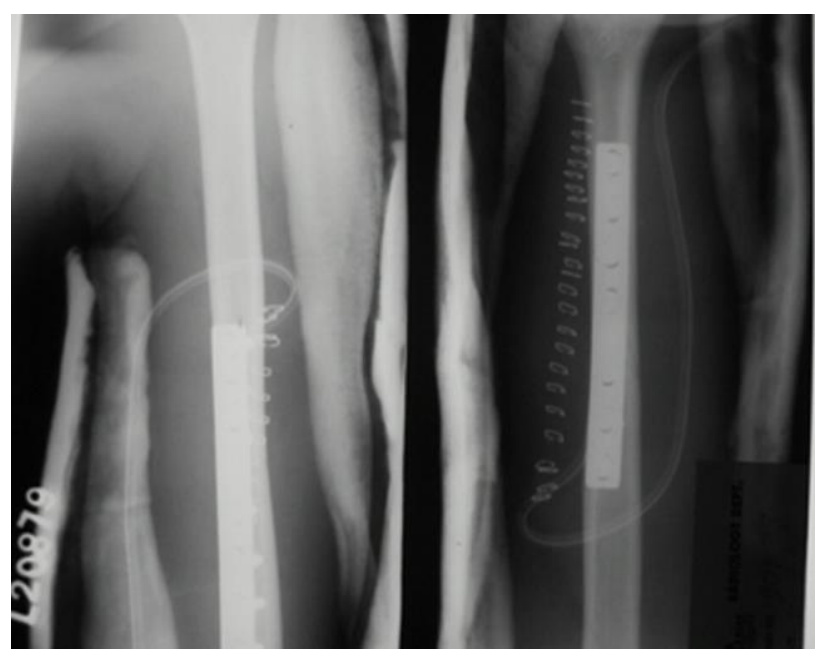

Figure 1 (f): Post-operative X-ray of arm (AP view).

\section{Non-operative management}

Non operative treatment consisted of $U$ slab hanging cast initially followed by functional brace application once swelling and pain subsided which takes usually 1-2 weeks. The functional brace was worn for a minimum of 8 weeks after fracture or until radiographic evidence of union was seen. Following healing, a course of 
physiotherapy for strengthening was prescribed. All patients were followed up to an average period of 1 year. Regular follow up was done 3 weeks for first 3 month, then once a month for 6 months then once in 2 months after 6 months. X-rays were taken at each follow up visits to know about progressive fracture union and implant position (Figure 1g). Rehabilitation protocol followed which consist of active and passive shoulder (Pendulum exercises), elbow, forearm \& wrist exercises. Union was defined by the absence of functional pain and local tenderness at the fracture site and the presence of bridging callus in 3 of the 4 cortices seen on AP and Lateral views.

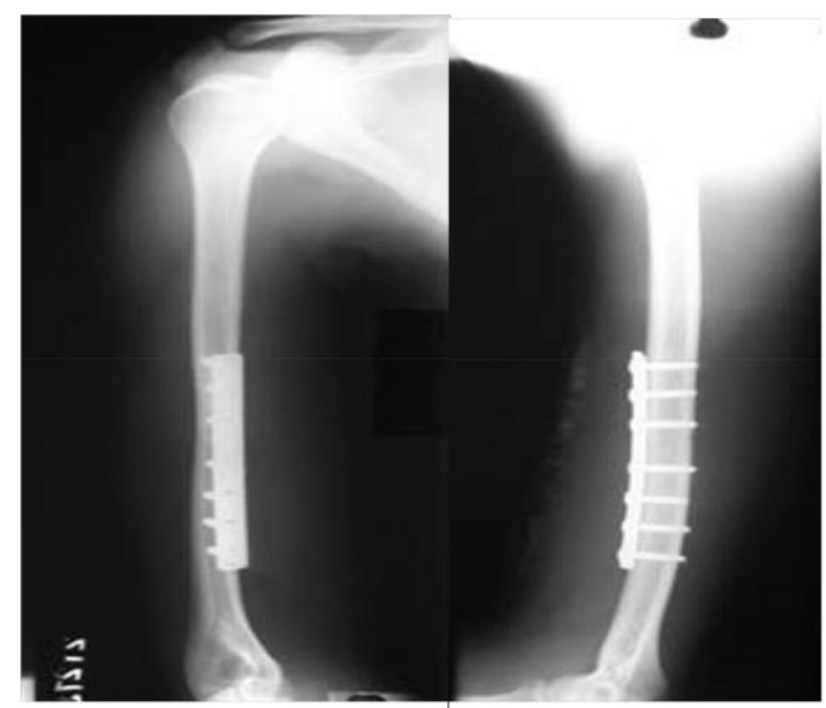

Figure 1 (g): Post-operative X-ray arm (AP/LAT view) at 20 weeks showing union.

\section{Functional outcome}

The functional outcome was measured by the disabilities of arm, shoulder and hand (DASH) 9 Questionnaire at nine month or at full recovery which ever was earlier. The DASH scoring system is a very useful tool to measure function of the upper limb developed by the American academy of orthopaedic (AAOS) and has been validated by various studies. The DASH questionnaire has thirty questions the answer of which are graded from one to five.

\section{The functional score is calculated by the formula}

DASH disability/symptom score $=\frac{\text { Sum of } \mathrm{n} \text { response }}{\mathrm{N}-1} \times 25$

where ' $\mathrm{N}$ ' is the number of responses. The best possible score is ' 0 ' and the worst possible score is ' 100 '. The functional outcome decreases as the score increases.

The result was then graded as excellent, good, fair, and poor (excellent - 0 to 20 points, good - 21 to 40 points, fair - 41 to 60 points, poor - greater than 60 points).
The time taken for radiological union and the functional outcome in the both groups were then compared.

\section{Statistical analysis}

Continuous variables are presented as mean $\pm \mathrm{SD}$, and categorical variables are presented as absolute numbers and percentage. The comparison of normally distributed continuous variables between the groups was performed using Student's t test. Nominal categorical data between the groups were compared using Chi-squared test or Fisher's exact test as appropriate. $\mathrm{P}<0.05$ was considered statistically significant.

$$
\mathrm{t}=\frac{\overline{\mathrm{X}}-\overline{\mathrm{X}}_{2}}{\mathrm{~S}_{\mathrm{X}_{1} \mathrm{X}_{2}} \sqrt{\frac{2}{n}}}
$$

Where, $S_{\mathrm{X}_{1} \mathrm{X}_{2}}=\sqrt{\frac{1}{2}}\left(\mathrm{~S}_{\mathrm{X} 1}^{2}+\mathrm{S}_{\mathrm{X} 2}^{2}\right.$

Here, is the grand standard deviation $1=$ group one, $2=$ group two. The denominator of $t$ is the standard error of the difference between two means. For significance testing, the degree of freedom for this test is $2 n-2$ where $n$ is the number of participants in each group. Statistical testing was conducted with the statistical package for the social science system version SPSS 17.0 Microsoft excel was used to draw tables, bar and pie diagrams and for the statistical analysis.

\section{RESULTS}

Majority of patients in non-operative had type of fracture oblique 11 out of $20(55 \%)$ and in operative group transverse 16 out of $20(80 \%)$. There was statistically difference in the two group $(\mathrm{p}<0.05)$ (Figure 2).

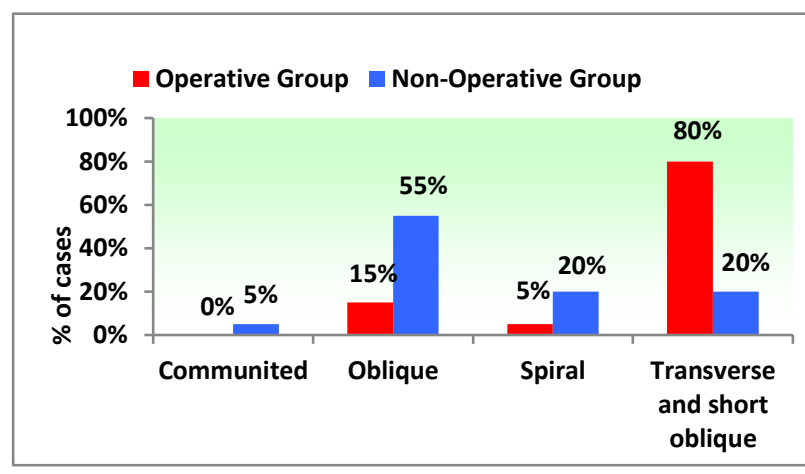

Figure 2: Comparison of type of fracture between operative and non-operative group.

Associated injuries were present in 8 patients of which 5 patients were in operative group while the rest 3 were in non-operative group. In the operative group one had tibial shaft fracture right, one had distal end radius fracture right, one had clavicle fracture right, one had both-bone forearm fracture right and one had radial shaft fracture left. (Table 1). In non-operative group. one had fibula 
fracture right. one had clavicle fracture right and one had distal end radius fracture left side (Table 2).

Table 1: Associated injuries in operative group.

\begin{tabular}{|ll|}
\hline $\begin{array}{l}\text { Operative group (associated } \\
\text { injuries) }\end{array}$ & No. of patients \\
\hline Tibia right & 1 \\
\hline Distal end radius right & 1 \\
\hline Clavicle right & 1 \\
\hline Forearm right & 1 \\
\hline radius shaft left & 1 \\
\hline Total & 5 \\
\hline
\end{tabular}

Table 2: Associated injuries in non-operative group.

\begin{tabular}{|ll|}
\hline $\begin{array}{l}\text { Non-operative group } \\
\text { (associated injuries) }\end{array}$ & No. of patients \\
\hline Clavicle right & 1 \\
\hline Tibia right & 1 \\
\hline Distal end radius right & 1 \\
\hline Total & 3 \\
\hline
\end{tabular}

In non-operative group, there were 2 (10\%) nonunion which were managed by open reduction and internal fixation by DCP with bone grafting. In operative group, there was $1(5 \%)$ nonunion in which patient refused for again surgery similarly study (Table 3 ).

Table 3: Number of unions.

\begin{tabular}{|c|c|c|c|}
\hline \multirow{3}{*}{ Group } & \multicolumn{2}{|c|}{ No. of patients } & \multirow[b]{2}{*}{ P value } \\
\hline & $\begin{array}{l}\text { No. of } \\
\text { union }\end{array}$ & $\begin{array}{l}\text { No. of } \\
\text { non-union }\end{array}$ & \\
\hline & $\mathbf{N}(\%)$ & $\mathbf{N}(\%)$ & \\
\hline $\begin{array}{l}\text { Operative } \\
\text { group }\end{array}$ & $19(95)$ & $1(5)$ & \multirow{3}{*}{1.000} \\
\hline $\begin{array}{l}\text { Non-operative } \\
\text { group }\end{array}$ & $18(90)$ & $2(10)$ & \\
\hline Total & $20(100)$ & $20(100)$ & \\
\hline
\end{tabular}

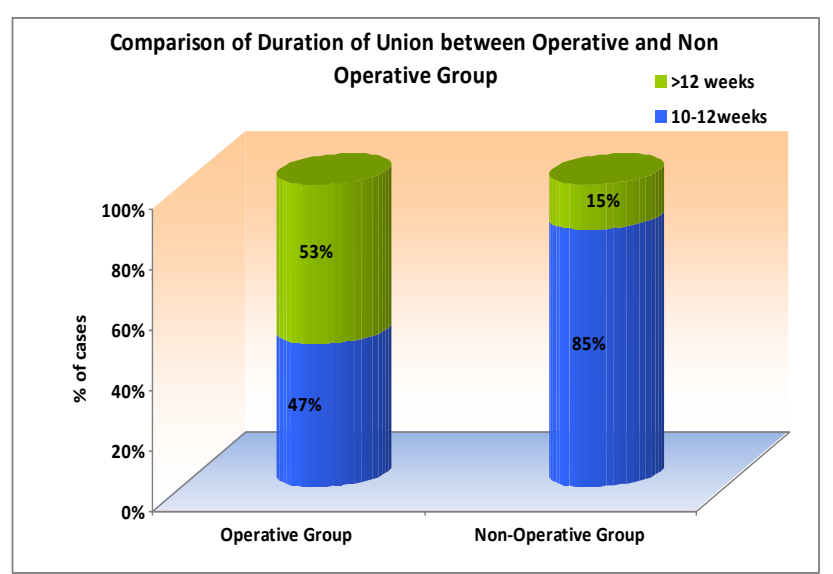

Figure 3: Comparison of duration of union between operative and non-operative group.
In our study patients group treated operatively the average time of union was 15.37 weeks whereas average time for union in patients treated non- operatively it was 11 weeks (Figure 3).

Among all 40 patients 14 had excellent results, 12 had good, 8 had fair and 6 had poor results. Functional outcome scores were better for operative group as compared to non- operative group with $\mathrm{p}<0.0001$ (Figure 4).

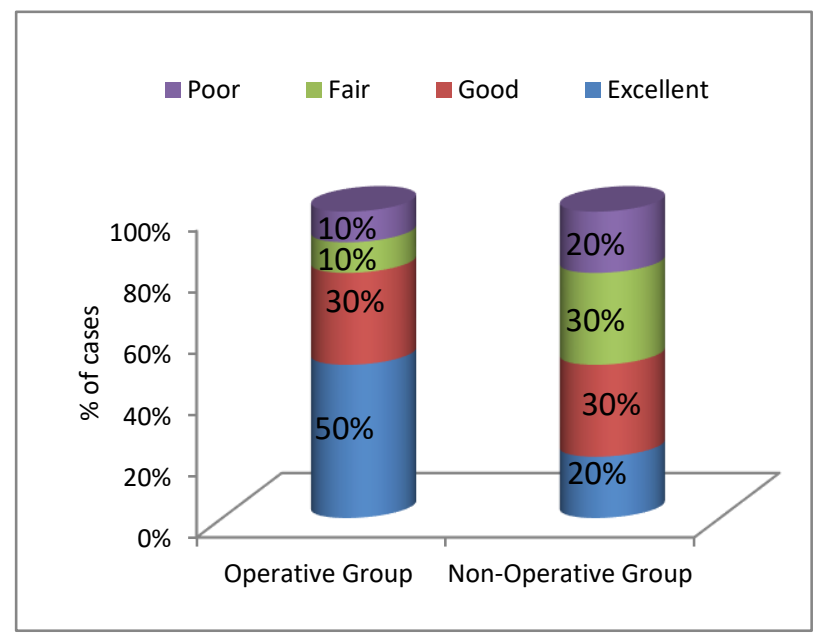

Figure 4: Comparison of functional outcome between operative and non-operative group.

In our study complications were seen in 11 of 20 operated patients. $3(15 \%)$ patients had superficial infections which were managed with antibiotics and dressings within 3 weeks. $2(10 \%)$ patients complained of hardware irritation and shoulder pain. 1 of them underwent plate removal while 1 refused for re-surgery. 1 (5\%) patient had implant failure with screw back out from the plate, he was managed with arm pouch immobilization as he refused for re surgery. 1 patient had post-operative radial nerve palsy (Figure 5).

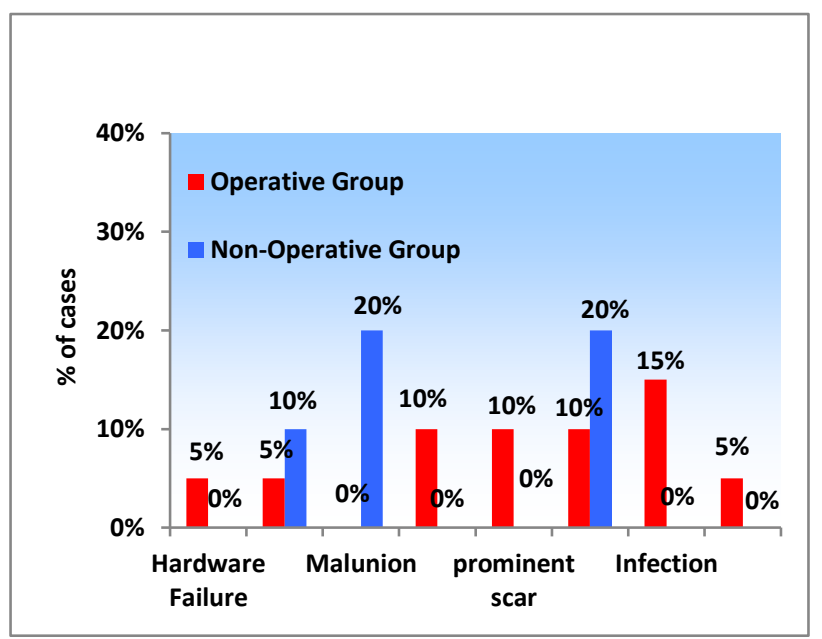

Figure 5: Comparison of adverse events between operative and non-operative group. 
Functionally patients in the operative group performed better than non-operative group. DASH scores were better for patients treated operatively (Table 4). ${ }^{9}$

Table 4: DASH score.

\begin{tabular}{|c|c|c|c|c|}
\hline \multicolumn{2}{|c|}{$\begin{array}{l}\text { Operative } \\
\text { group }(n=20)\end{array}$} & \multicolumn{2}{|c|}{$\begin{array}{l}\text { Non-operative } \\
\text { group }(n=20)\end{array}$} & \multirow{2}{*}{ P value } \\
\hline $\begin{array}{l}\text { Mean } \pm \\
\text { SD }\end{array}$ & $\begin{array}{l}\text { Min - } \\
\text { Max }\end{array}$ & $\begin{array}{l}\text { Mean } \pm \\
\text { SD }\end{array}$ & $\begin{array}{l}\text { Min - } \\
\text { Max }\end{array}$ & \\
\hline $\begin{array}{l}23.40 \pm \\
22.87\end{array}$ & $0-85$ & $\begin{array}{l}41.35 \pm \\
16.32\end{array}$ & $16-65$ & $0.007 *$ \\
\hline
\end{tabular}

\section{DISCUSSION}

Previously non-operative treatment modality has been the mainstay of humeral shaft fracture management for ages. However, it has been associated with varying degree of morbidity and complications like non-union and malunion etc. Our study was a prospective and comparative study done at Hindu Rao Hospital, Delhi from May 2017 to May 2018. Twenty patients with humerus shaft fracture were treated operatively and twenty patients were treated non-operatively. The goal of our study was to determine whether DCP of humerus shaft fractures would give better results in terms of union rate, good functional outcome and fewer complications in operative group. In operative group 11 patients suffered road side accident (RSA), 7 met with direct injury and 2 suffered twisting injuries. In non-operative group 12 patients suffered road side accident (RSA), 6 met with direct injury and 2 suffered twisting injuries. In both groups RSA was the most common mode of injury mean age for the patients in operative group was 37.65 years (22-50 years) while in non-operative group was 32.7 years (18-50 years). Majority of patients in non-operative had type of fracture oblique 11 out of $20(55 \%)$ and in operative group transverse 16 out of $20(80 \%)$. there was statistically difference in the two group $(\mathrm{p}<0.05)$ (Figure 2). In operative group 15 patients were male and 5 patients were female. In non-operative group 14 patients were male and 6 patients were female. Majority of the fractures were left sided in both operative $(60 \%)$ as well as in nonoperative group $(60 \%)$. Associated injuries were present in 8 patients of which 5 patients were in operative group while the rest 3 were in non-operative group. In the operative group one had tibial shaft fracture right, one had distal end radius fracture right, one had clavicle fracture right, one had both-bone forearm fracture right and one had radial shaft fracture left (Table 1). In nonoperative group. one had fibula fracture right. one had clavicle fracture right and one had distal end radius fracture left side (Table 2). These fractures were managed appropriately. In 10 patients $(50 \%)$ surgery was done within first week while in rest surgery was done when they were fit for anaesthesia. During surgery every effort was made to achieve anatomical reduction. The aim was to place at least four screws in the proximal and distal to main fragments through both cortices of the bone. The length of the plate to be used was based on the extent of commination of the fracture site. All patients were immobilized in brace for 1 week. Later on, mobilization was done under supervision once their pain subsided. Patients in non-operative group were managed on OPD basis with splint /hanging cast. It was exchanged for functional bracing 1 to 2 weeks after injury as swelling and pain subsides. The functional brace was worn for a minimum of 8 weeks after fracture or until radiographic evidence of union seen. In our study average time for union in patients treated non operatively was 11 weeks (Figure 3) which is similar to studies of average time 10 to 12 weeks. ${ }^{10,11}$ In patients group treated operatively it was 15.37 weeks similar to the study average time of union was 19 weeks done by Bell et al. ${ }^{12}$ Delayed union was diagnosed when the fracture failed to unite by end of 3 rd month and a non-union when union was arrested beyond 6-8 months. ${ }^{13}$ Delayed union in operative group was seen in $2(10 \%)$ patients, in whom fracture united at 20 and 24 weeks and in non-operative $4(20 \%)$ patients which united at 16 to 18 weeks. In non-operative group, there were $2(10 \%)$ nonunion which were managed by open reduction and internal fixation by DCP with bone grafting. In operative group, there was $1(5 \%)$ nonunion in which patient refused for again surgery similarly study (Table 3). The rate of nonunion in study done by Healy et al. ${ }^{14} 1987$ was $13 \%$ and $8 \%$ in non-operative and operative groups respectively by Rubel et al. ${ }^{15} 2002$ highest incidence of nonunion is $13 \%$ for both non operative and operative management. The fracture was considered to be united when clinically there was no tenderness, radio graphically fracture line was not visible and fully unprotected function of limb was possible. In our study complications were seen in 11 of 20 operated patients. $3(15 \%)$ patients had superficial infections which were managed with antibiotics and dressings within 3 weeks. 2 (10\%) patients complained of hardware irritation and shoulder pain. 1 of them underwent plate removal while 1 refused for re-surgery. 1 (5\%) patient had implant failure with screw back out from the plate, he was managed with arm pouch immobilization as he refused for re surgery. 1 patient had post-operative radial nerve palsy (Figure 5). The reported incidence of from 2$5 \% .^{13,16}$ The patient had complete recovery by 16 weeks. None of the patient in the non -operative group had radial nerve palsy after immobilization. Four of the patients had malunion in non-operative group no treatment was given to them. Functionally patients in the operative group performed better than non-operative group. DASH scores 9 were better for patients treated operatively (Table 4). Rapid functional restoration and patient satisfaction was better in the operative group. ${ }^{17,18}$ The improvement in scores was clinically relevant as well as significantly superior statistically. Findings of our study suggested that rigid internal fixation and early mobilization of fresh fracture shaft of humerus gives immediate pain relief and prevents development of shoulder and elbow stiffness and is associated with lower incidence of non-union and malunion. Among the 40 patients 14 had excellent 
results, 12 had good, 8 had fair and 6 had poor results (Figure 4). Functional outcome scores were better for operative group as compared to non-operative group with $\mathrm{p}$ value $<0.0001$.

Although the results of operative intervention may be good in young individuals with displaced mid shaft fractures, surgical intervention should be selected depending upon the risk/benefit ratio for the patient individually. Patient's non-compliance with the postoperative regimen could be a cause of the failure of operative treatment if the patient is not motivated well before surgery..$^{19,20}$

\section{CONCLUSION}

Majority of fractures in the study were either transverse or oblique middle third shaft of humerus with most of them being closed injuries. Dynamic compression plating of humerus is better method than conservative method because it achieves higher union rates and avoids prolonged immobilization which leads to stiffness and induces dystrophy. It also gives early active and pain free mobilization. Good surgical skills, anatomical knowledge, good preoperative planning, minimal soft tissue dissection, adherence to AO principles, aseptic precautions, post-operative physiotherapy, patient education and early mobilization, the dynamic compression plating of fracture shaft of humerus gives excellent results as compared to non-operative management. Complications of surgery included superficial infection, radial nerve palsy, stiffness of elbow and shoulder joint, delayed union and non-union. These are also very rare if strict asepsis, meticulous dissection, stable fixation and adequate mobilization are undertaken.

\section{ACKNOWLEDGEMENTS}

Contributing authors are sincerely thankful to all patients, who have participated in this study and consented for their photographs including X-rays.

Funding: No funding sources

Conflict of interest: None declared

Ethical approval: The study was approved by the institutional ethics committee

\section{REFERENCES}

1. Zuckerman JD, Koval KJ. Rockwood CA, Green DP, Bucholz RW, Heckman JD. Fractures of the shaft of the humerus. In: Rockwood and Green's Fractures in Adults. 4th Edition. Philadelphia: Lippincott-Raven 1996;1025-53.

2. Epps CH, Grant RE, Rockwood CA, Green DP, Bucholz RW. Fractures of the shaft of the humerus. In: Rockwood and Green's Fractures in adults. 3rd ed. Philadelphia: Lippincott Williams \& Williams 1991.
3. Tsai CH, Fong YC, Chen YH, Hsu CJ, Chang CH, Hsu HC. The epidemiology of traumatic humeral shaft fractures in Taiwan. Int Orthop 2009;33:463-7.

4. Sarmiento A, Zagorski JB, Zych GA, Latta LL, Capps CA. Functional bracing for the treatment of fractures of the humeral diaphysis. Journal of Bone \& Joint Surgery American Volume. 2000;82(4):478-86

5. Allgower M, Perren S, Matter P. A new plate for Internal Fixation the Dynamic Compression Plate (DCP). Injury 1970; 2:40-47.

6. Perren SM, Berger RM, Steinemann S, Muller ME, Allgower M. A dynamic compression plates. Acta Orthop Scand 1969;125:31-41.

7. Foster RJ, Dixon GJ, Bach AW, Appleyard RW, Green TM. Internal fixation of fractures and nonunions of the humeral shaft. Indications and results in a multi-center study. J Bone Joint Surgery Am 1985;67:857-64.

8. Rogers J, Bennett J, Tullos H. Management of concomitant ipsilateral fractures of the humerus and forearm. J Bone Joint Surgery Am 1984;66:552-6.

9. Atroshi I, GummessonI, Andersson B, Dahlgr E, Johannson A. The Disability of the Arm, Shoulder and Hand (DASH) outcome questionnaire. Actaorthopsc 2000;71(6):613-18.

10. Stewart MJ, and Hundley JM. Fractures of the Humerus: A Comparative Study in Methods of Treatment. Journal of Bone and Joint Surgery 1955; 37(A):681.

11. Klenerman L. Fracture of the shaft the humerus. J. Bone Surgery 1966;48B:105-11.

12. Bell MJ, Beauchamp CG, Kellam JK, Mcmurtry RY. The Result of plating Humerus shaft fractures in patients with multiple injuries. The sunny brook experience. J Bone Joint Surg Br 1985;67-B:293-96.

13. Rosen. H. The treatment of non-union and pseudoarthrosis of the humerus shaft. Orthopaedic Clinics of North America 1990;21(4):725-42.

14. Healy WL, White GM, Mick CA, Brooker AF, Weiland AJ. Nonunion of the humeral shaft. ClinOrthop 1987;219:206-13.

15. Rubel I, Kloen P, Campbell D et al. Open Reduction and Internal Fixation of Humeral Non-Unions, A Biochemical and Clinical Study. J Bone Joint Surg (Am). 2002;84:1315-22.

16. Crenshaw AH. Fracture of humeral shaft with radial nerve palsy. In: Crenshaw AH, ed. Campbell's operative orthopaedics. Eighth ed. St. Louis: Mosby Year Book. 1992;2:1016.

17. Koch PP, Gross DFL, Gerber C: The results of functional (Sarmiento) bracing of humeral shaft fractures, J Shoulder Elbow Surg. 2002;11:143.

18. Haveri SM, Maheswarappa D. Study of functional outcome of humerus shaft fracture in adults treated with dynamic compression plating. J Sci Soc. 2012;39:114-7.

19. Jupiter JB. Complex non-union of the humeral diaphysis: treatment with a medial approach, an 
anterior plate and a vascularized fibular graft. J Bone Joint Surg. 1990;72(A):701-7.

20. Kolb DN, Knoefel WT, Schweiberer L. The treatment of humeral shaft fractures. Results of a prospective AO multicenter study. Unfallchirurg. 1991;94(9):447-54.
Cite this article as: Gaur N, Singh NK. A

comparative study of operative dynamic compression plating versus non-operative management in fracture shaft of humerus. Int J Res Orthop 2020;6:374-81. 